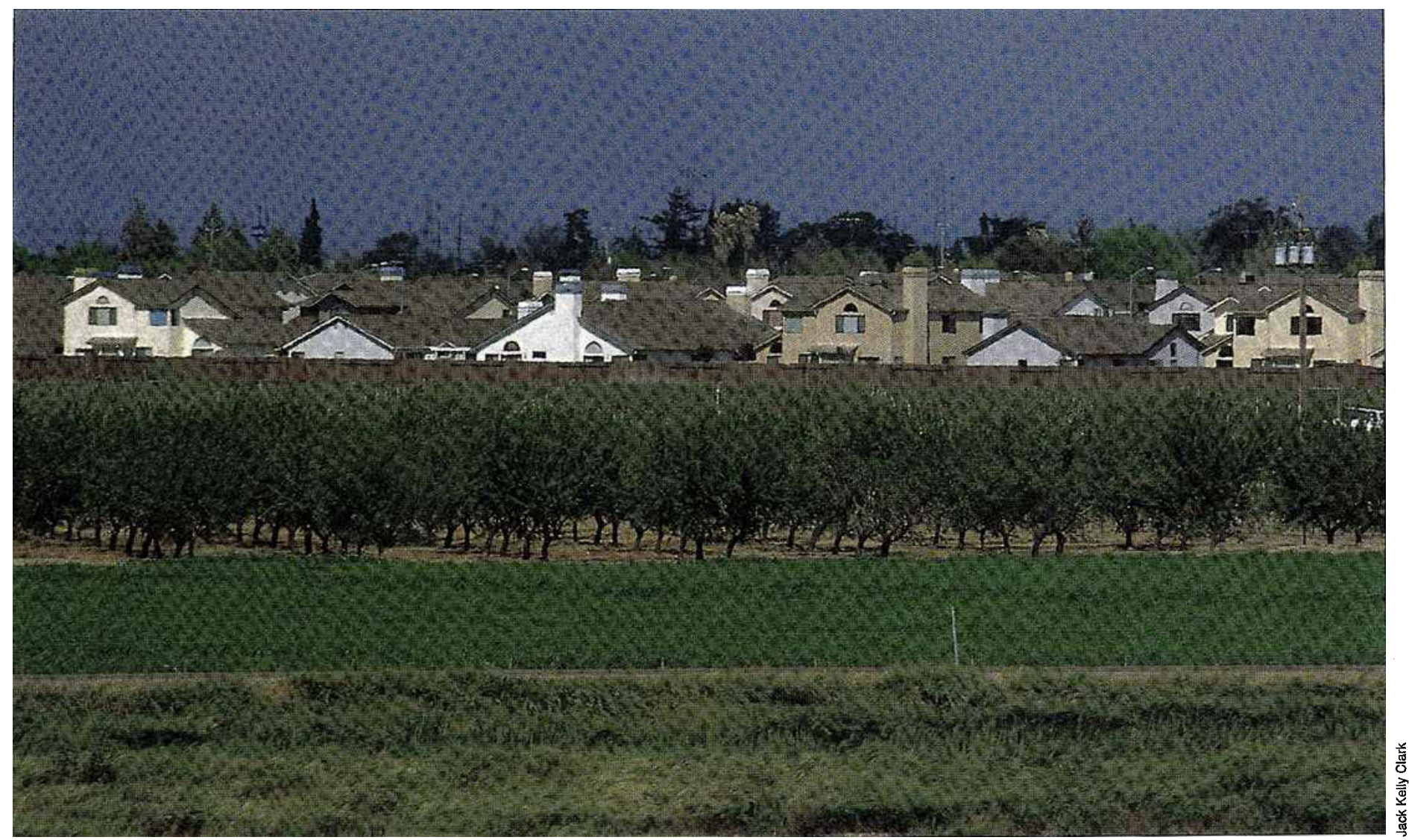

\title{
Keeping the valley green: a public policy challenge
}

Almond orchard in front of a subdivision at Manteca in San Joaquin County.

\author{
UC Agricultural Issues Center*
}

\section{In California's Central Valley, popu- lation expansion and economic de- velopment threaten one of the world's most productive agricul-} tural systems. In 1989 and 1990, the UC Agricultural Issues Center undertook the first comprehensive analysis of the demographic and resource problems that result, as well as the "government gridlock" that is one obstacle to their solution. The multi-disciplinary project involved more than 60 university researchers on five UC campuses, as well as other experts from various public and private agencies. The following report draws heavily on that analysis, "California's Central Valley - Confluence of Change." $†$
Although California's population has shown explosive growth since the 1950s, the Central Valley's population did not begin to boom until the 1980s. For several decades after World War II, economic and population expansion was concentrated around the coastal metropolitan complexes of Los Angeles, San Diego and the Bay Area. During that era, important farmland areas were lost but damage to California agriculture was minimized as producers relocated. Dairies and citrus groves from Southern California and fruit orchards from the Santa Clara Valley moved inland to the Central Valley. Although the state was rapidly urbanizing, agricultural acreage actually increased including hundreds of thousands of acres irrigated by the State Water Project.

In the 1980 s, however, a new, inlandoriented pattern of urban growth evolved, driven by scarcity of land and spiraling prices in the metropolitan coastal areas, the penchant of Californians for suburban, single-family residences, and a freeway system that made long commute distances feasible. The appearance of high-technology and other new industries in the Valley added to inland growth pressure.

During the 1980s, the Central Valley's population increased $30 \%$. The newcomers

*Authors include Harold O. Carter, Professor, Department of Agricultural Economics, UC Davis, and Ray Coppock, Lynne Kennedy, Carole Nuckton and Julie Spezia, staff of the UC Agricultural Issues Center (AIC).

tGroup leaders of the AIC's Central Valley project were UC Professors Ed Blakeley (city and regional planning); William Rains (agronomy and range science); Warren Johnston, Richard Howitt, and Elmer Learn, (agricultural economics); Kenneth Tanji (land, air and water resources); Al Sokolow (political science), and Paul Jovanis (civil engineering). 

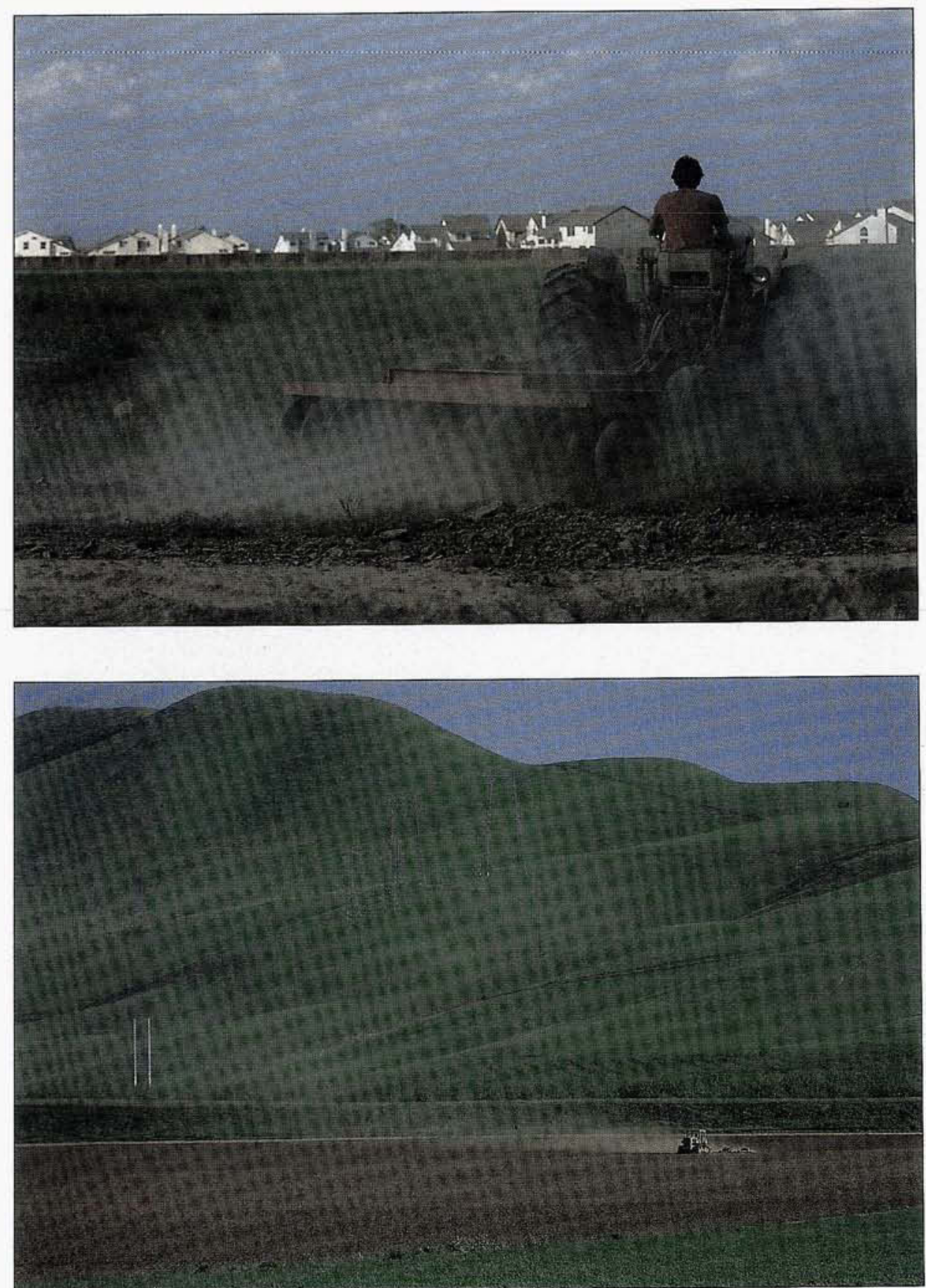

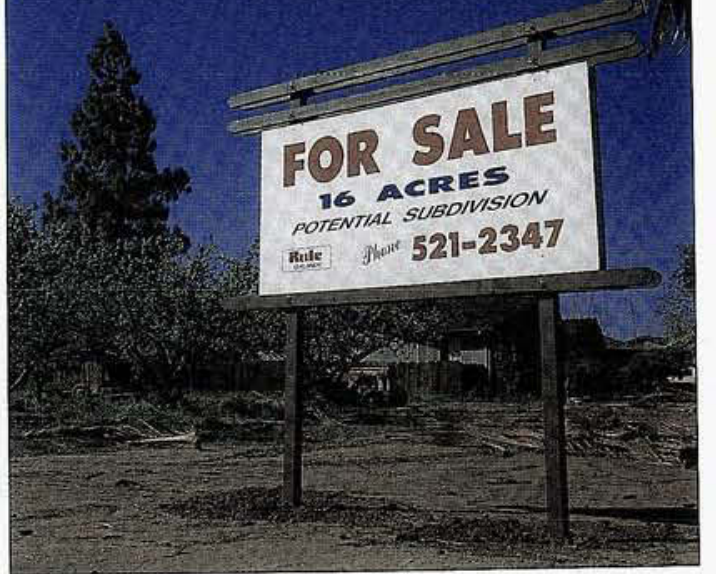

As population grows in number and diversity, changing land use may create conflict, particularly at the borders between agricultural and urban areas. At top left, a tractor driver discs a field next to a Modesto subdivision - either to plant crops or, alternately, to plant houses. Top right shows a sign outside Patterson on the Valley's east side. At left, vast tracts of agricultural land remain intact, including this alfalfa field near Westley, west of Modesto. Below, Highway 120 near Manteca is a route for increasing numbers of Bay Area commuters. At bottom, an industrial warehouse overlooks fields of barley near Modesto. (All photos by Jack Kelly Clark)

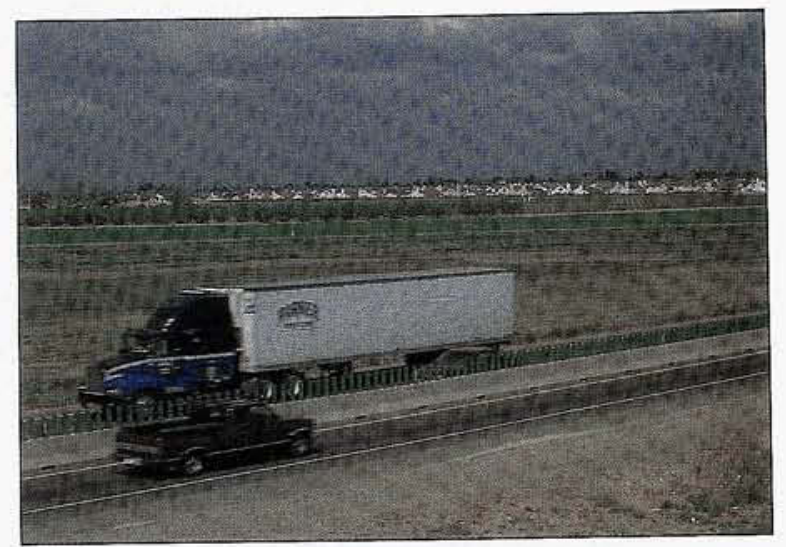

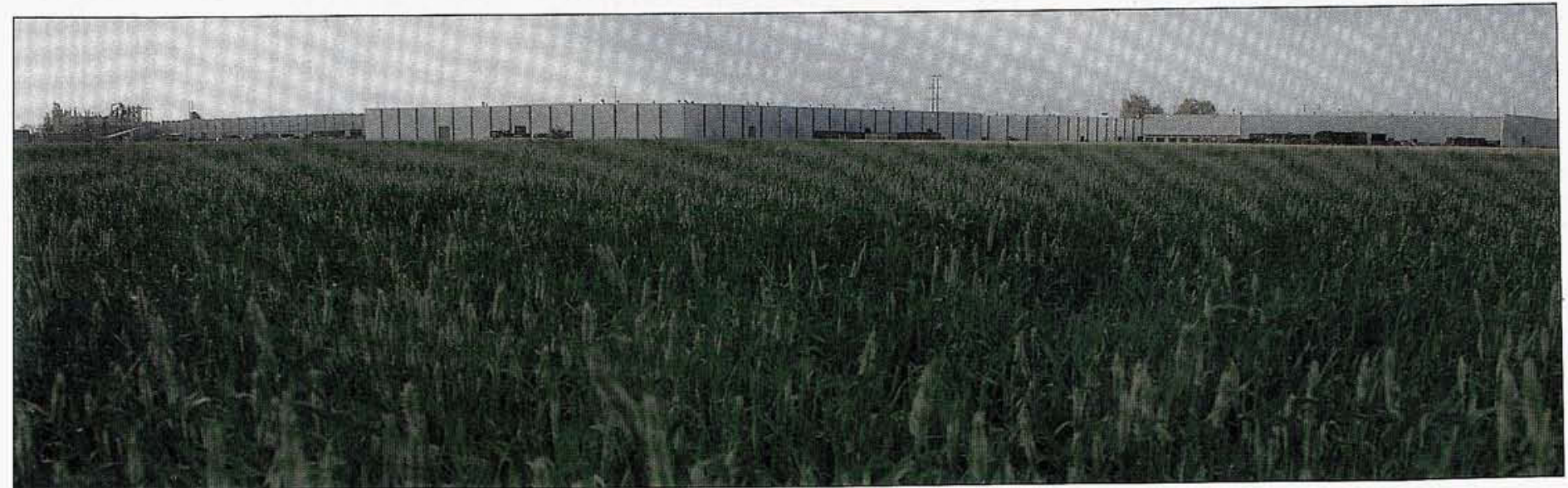




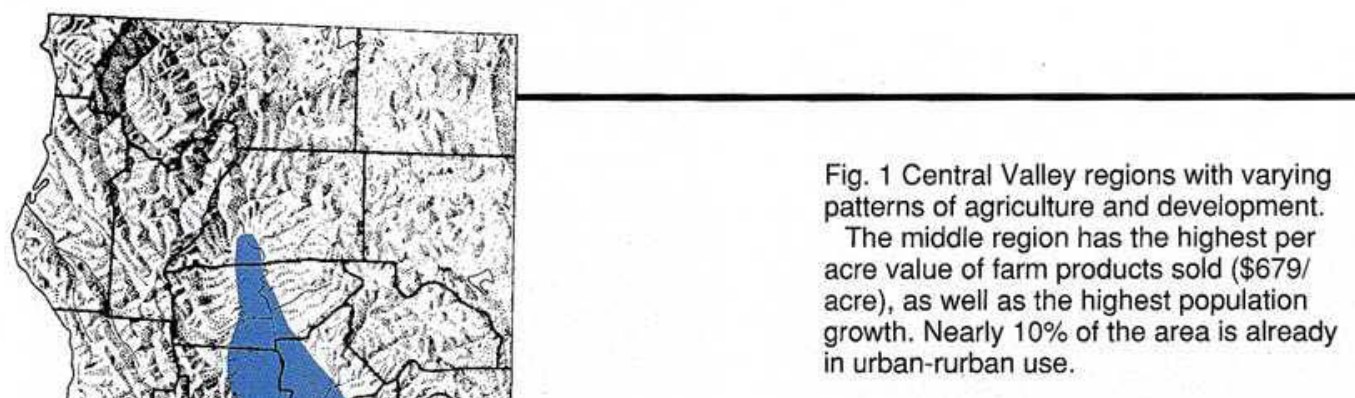

Northern region: Shasta, Tehama, Butte, Glenn, Colusa, Yuba and Sutter Counties

Middle region: Yolo, Sacramento, Solano, San Joaquin and Stanislaus Counties

\&

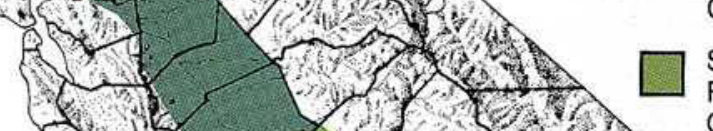

Southern region: Merced, Madera, Fresno, Kings, Tulare and Kern Counties

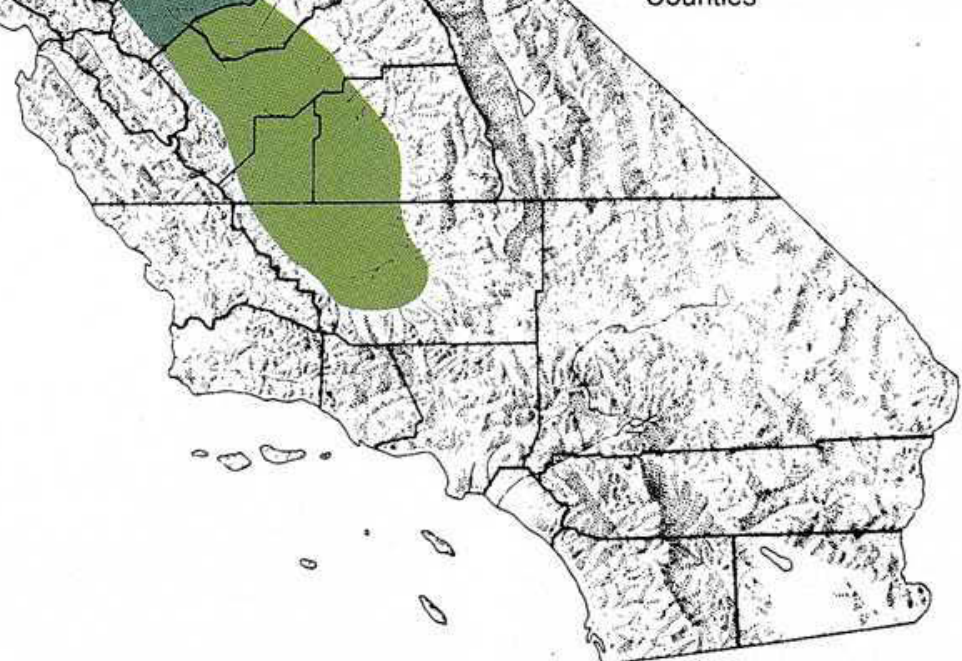

\section{Land in farms}

Cropland Irrigated land

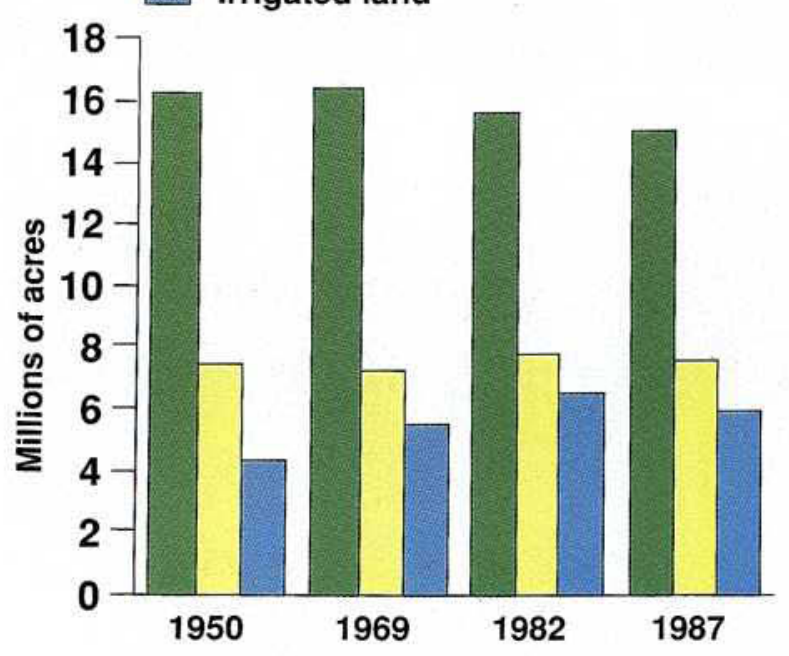

Fig. 2 Agricultural land base for Central Valley farms, ranches or chards and vineyards.

The Central Valley will be the next region to feel the effects of California's dramatic population growth. Over the last 40 years, as the state's population grew from 10 to 30 million, urbanization led to a $53 \%$ reduction in harvested acreage in coastal valleys between San Francisco and the Mexican border. During the same period, agricultural land in the Central Valley declined $9 \%$ (from 16.3 to 14.8 million acres.) But as the Central Valley's current growth accelerates - and conservative estimates project the 4.5 million inhabitants will grow to 7.5 million by 2005 the pressure to convert land and agricultural resources will further intensify. were diverse - Bay Area commuters, employees in the Valley's growing industrial base, retirees, immigrants from Latin America and Southeast Asia. As a result, a growth-induced environmental crisis is at hand in the once-rural Central Valley. It involves not just land use, transportation and housing, but also air pollution, water resources, wildlands and open spaceand, in conjunction with all of these, the future of the agricultural system.

Because agriculture and development patterns vary along the length of the Valley, they are best viewed as occurring in three distinct regions, shown in figure 1 :

- The upper Sacramento Valley, with less development pressure so far.

- The middle region, under powerful pressure from Bay Area spillover and from its own commercial and industrial development. Of the three regions, it has the smallest average farm size, reflecting both mature development and ongoing parcelization. It also has the most rapid population growth, much of it spreading along freeway-centered corridors. Nearly $10 \%$ of this region is already in urban or "rurban" use, ("Rurban" refers to the parcelization of agricultural areas into rural homesites, ranchettes and small farms.) - The southern region, center of largescale, intensive agriculture, with its own rapidly expanding metropolitan areas and with spillover from the Los Angeles basin.

So far, the Central Valley's vast agricultural economy remains intact, but the trend toward urbanization is clear. If growth in the lower two-thirds of the Valley continues at the same rate as in the decade before 1986, an American Farmland Trust survey showed that farmland acreage equal to virtually all the cropland in Stanislaus County will be lost within 20 years.

It is likely, however, that the rate of farmland conversion will be even greater than that. Physical, economic, demographic and social forces have encouraged or accommodated to growth in the past, and - despite local pressures to the contrary - there is little evidence that they will not continue. A recent forecast is for a statewide population increase of 10 million by the year 2005. Three million or $30 \%$ of those new Californians will live in the Central Valley.

\section{New times, new problems}

Although it derives from California's four decades of continuous growth, the 
current crisis in the Central Valley has its own characteristics:

- This time, there is no outlying area where agriculture can escape. For the state's agriculture and for urban development, the Valley is the last frontier.

- City growth in the Valley is moving almost entirely onto intensively cultivated croplands, with spillover effects on the 10 million acres of foothill lands that ring the Valley.

- Central Valley farmland extends over vastly more area than in any of the previously-urbanized coastal valleys. The Santa Clara Valley, for example, filled up with houses and industries in relatively few years, destroying agriculture as an economic and environmental force. However, urban areas in the Valley currently cover about 560,000 acres, equivalent to $7 \%$ of its farmland. Doubling today's population at the same rate of urban land-use intensity would bring the total urbanized area to $14 \%$. That would be a substantial loss, but millions of acres of cropland would remain. There will be a long, perhaps an indefinite, period when expanding cities in the Valley will co-exist with vast amounts of open space - mostly farmland.

Compared to experience elsewhere in California, therefore, urbanization in the Central Valley will put less immediate pressure on the total farmland resource. It will, however, create widespread and long-range problems involving the mix of agriculture with residential, commercial and industrial development. The fundamental question for the Valley's future is: How can agriculture continue to thrive in an increasingly urbanized environment?

\section{Threats to land, air, water}

Prime farmland, the irreplaceable resource, is under conversion pressure in many parts of the Valley. Impacts of commuters from the Bay Area already are apparent in communities as far inland as Modesto. At the same time, regionally-oriented growth is taking place in the Sacramento and Fresno areas. Most of the Highway 80 corridor between the Bay Area and Sacramento already is urbanizing; future development along Highway 99 may create what has been called a. "multi-nucleated linear metropolis." Within a few years, commuter spillover may trigger substantial growth along the West Side. Another possibility is "new cities" along the Valley fringe, possibly in the lower foothills. (So far, such proposals have been blocked by environmental concerns, including preservation of endangered species.)

Besides farmland conversion, air pollution is another by-product of population. and economic growth that threatens agriculture and the agricultural-urban relationship. The geography and weather patterns in the Valley make it as potentially vulnerable to extreme air pollution as the South Coast air basin. Prevalent ozone levels already are causing yield losses in more than two dozen important Valley crops - more than $20 \%$ for melons, beans and grapes and from $9 \%$ to $15 \%$ for alfalfa, cotton, citrus and potatoes. Just meeting today's moderate state standards for ozone would, for example, increase cotton yields by $10 \%$.

The economic viability of the Valley's agricultural system may depend on control of air pollution - as will the health and quality of life of all Valley residents.

What about the water resource? Wherever the Valley's new residents settle, on former farmland or in the foothills, they will be "upstream" of agriculture in terms of water use. They will buy water formerly used by agriculture, and they will be able to pay higher prices for it. Where farmland with an adequate irrigation supply is developed, that water may be available and sufficient for the new uses. But if competition develops for scarce water, farmers will be out-bid and farmland will go dry. The current extended drought and cutbacks on irrigation water deliveries portend possible constraints on Valley agriculture as population growth continues.

Ground water contamination creates an even more immediate conflict of interest between Valley farmers and expanding cities. Nitrates and pesticides, particularly DBCP, in drinking water sources already exceed state standards in several parts of the Valley: Maintenance of ground water quality for human use may be a future constraint on Valley agriculture.

High water tables, salinity and trace element contamination - particularly naturally-occurring selenium - along the Valley trough and on the West Side comprise another environmental problem with implications for future patterns of agriculture and urbanization in the Valley. If the drainage problem is solved, or partially solved, the economic and environmental presence of agriculture in the Valley will be strengthened. If not, even more acres of farmland will be lost to salinization than
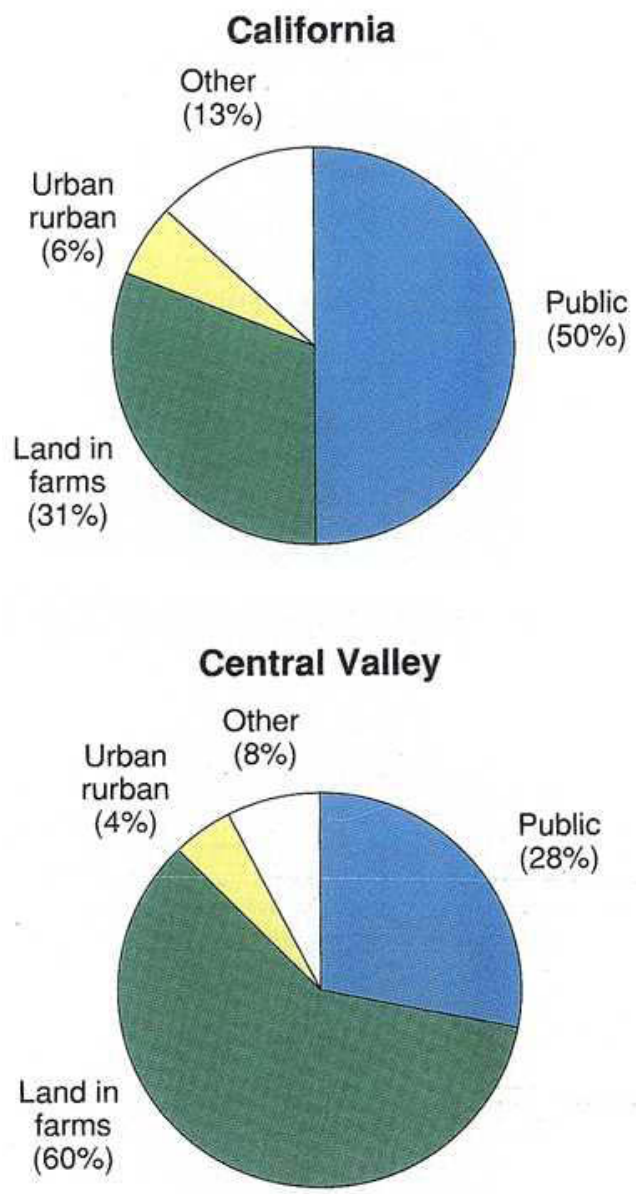

Fig. 3 Land under public and private ownership in California and the Central Valley.

Privately-owned land constitutes $72 \%$ of the Central Valley, compared to $50 \%$ statewide. Because most of the Central Valley's privately owned land is in farms (83\%), a growing population will exert increased pressure to convert private agricultural lands to higher intensity nonagricultural uses. 


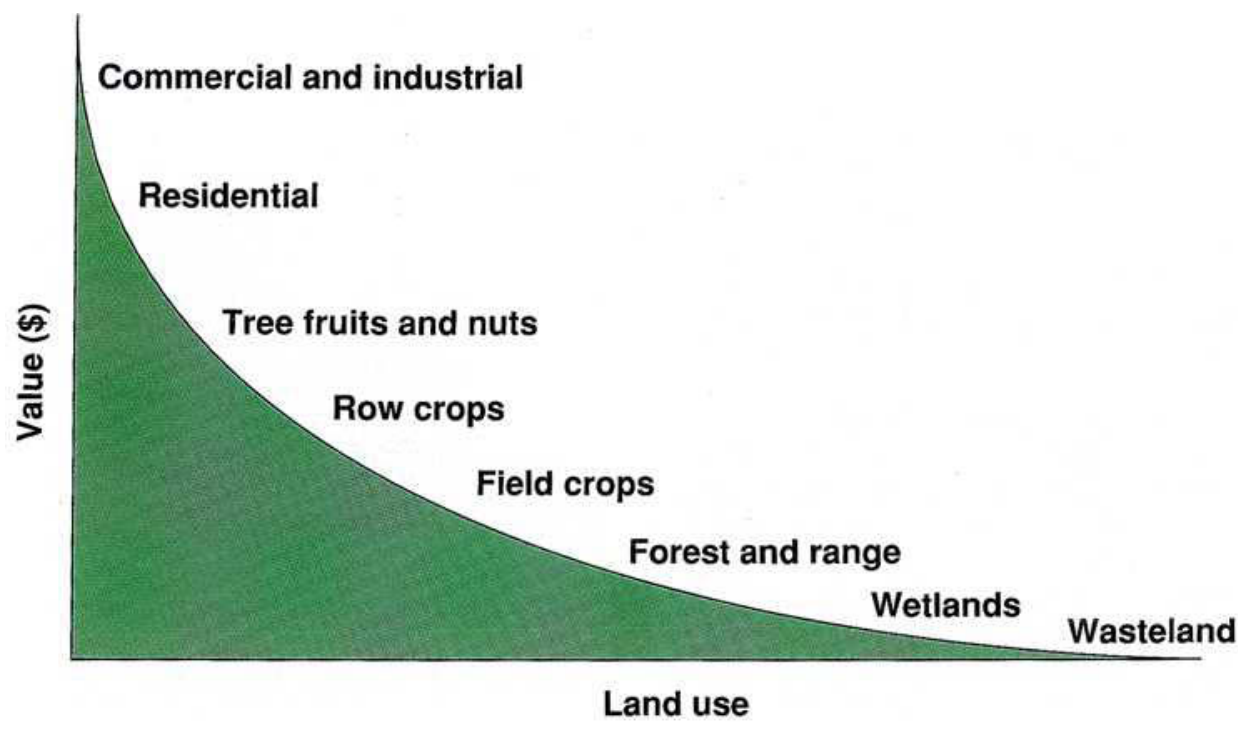

Fig. 4 Generalized profile of land use by economic value.

Owners of private property have economic incentives to use land for the purpose that promises the highest return, sometimes referred to as the highest and best use. However, land use becomes controversial when the use promising highest return confers external costs on other property owners or conflicts with societal interests. Then the criterion of highest and best use shifts from one of simply maximizing return to one in which economic return is adjusted for external costs and intangible social values.

to urbanization in the near future. Vast areas of waterlogged and possibly contaminated soils will create a challenge for landuse planners. Urbanized areas conceivably could be located where shallow water tables prohibit agriculture; however, saline or contaminated ground could pose health or environmental barriers.

\section{Threshold for system damage}

Localized tradeoffs between urban and farmland uses undoubtedly will continue and intensify. Valley-wide agriculture, meanwhile, has not been fundamentally reshaped so far by loss of farmland. A crucial question in the long run is: What is the extent of resource deterioration and what are the limits of urbanization beyond which the agricultural system itself will falter? If that happens, both the agricultural economy and the Valley's openspace human environment will be threatened.

Let us consider two extreme scenarios. In one, an unplanned, sprawling megalopolis grows up alongside, or randomly scattered among, vast acreages of non-urbanized land. Without planned protection, much agriculture becomes economically marginal because of the added costs of re- duced parcel size and piecemeal environmental regulations, among other things. Undeveloped areas of former farmland contribute little in either economic or environmental values. The threshold of system viability eventually is crossed and Valley agriculture dies a slow death.

In the other scenario, urbanized areas are interspersed with designated and planned areas of irrigated farmland (and occasional wildlands) along the length of the Valley. This pattern might develop in either or both of two ways. The first is a California version of the "landscape" approach used in parts of Western Europe. Local communities might consider development patterns that accommodate both farmers and suburbanites, with fingers of farmland separating areas of housing and shopping. The second would occur where cropping patterns or cultural practices require economies of scale. In these locales, tightly-drawn urban limit lines would separate farmland from city.

\section{Requirements for change}

Because Valley agriculture remains strong as a regional system, there is still time to influence the outcome with public policy decisions. Much of the Central
Valley's agricultural open space is not simply undeveloped land, ripe for conversion to other uses, but is already committed to what is, in the broadest sense, its highest and best use - agriculture. However, as population increases, the economic and environmental problems of urban-agricultural coexistence will require changed attitudes and practices on both sides.

Chances for a favorable scenario depend on public awareness of interconnected Valley-wide problems and on planning - particularly regional land-use planning. The ideal scenario would include the following elements:

- Local communities would operate within guidelines protecting the interests of their neighboring communities and the region as a whole. Regional governments would address certain planning problems - air pollution control and transportation, for example - which inevitably cross over local government boundaries.

- Local and regional governments would strengthen and expand "right to farm" ordinances. Land preservation programs that allow farmers to operate economically and yet provide an adequate tax base for local government are crucial. The fiscal constraints facing both city and county governments must be addressed if "zoning for dollars" (encouraging development to increase sales tax revenue) is to cease.

- Suburbanites would learn to tolerate certain levels of neighboring farm activity, and manage problems of trespassing and vandalism. Local direct marketing of fresh farm produce would be encouraged.

- Farmers in urbanized regions would emphasize sustainable, low-input practices; avoid open field burning, aerial application of pesticides and various other cultural practices; and, if necessary, change cropping patterns.

- Agriculture would internalize costs of its pollution into the production system, or agricultural pollution control programs might be partially subsidized to achieve regional environmental benefits.

Although population growth and other forces will powerfully influence the future, we still have choices. The unprecedented challenge is to capture the benefits of growth while preserving the Valley's agricultural base and maintaining the quality of life for millions of future Valley residents. 